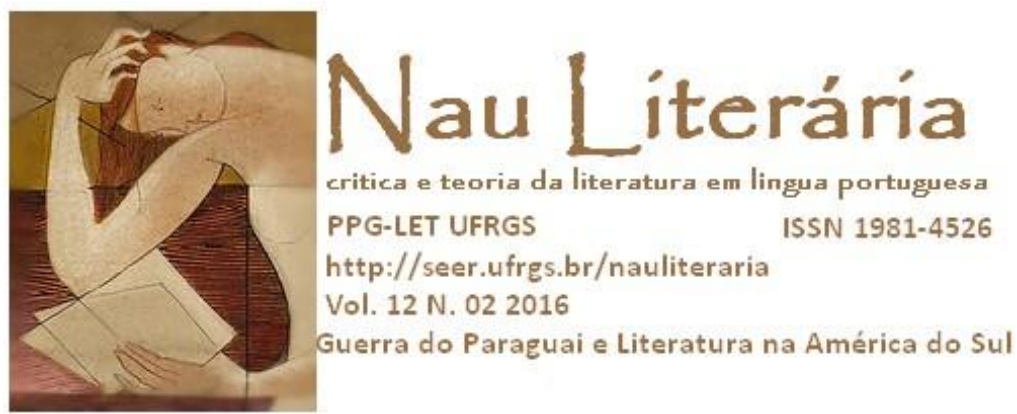

\title{
Melbourne, Paraguai: Gerald Murnane e a escala da literatura
}

\author{
Ian Alexander \\ UFRGS
}

Resumo: O presente artigo trata do conto "The Battle of Acosta Nu" [A batalha de Acosta Nu], do australiano Gerald Murnane, que aparece no livro Landscape with Landscape [Paisagem com paisagem], de 1985. Em primeiro lugar, explica o fundamento histórico do conto - o contexto australiano na década de 1890 e a fundação da colônia Nova Austrália no interior do Paraguai - e oferece um descrição geral da obra de Murnane na década de 1980. Depois, analisa “A Batalha de Acosta Nu" em relação ao romance anterior de Murnane, The Plains [A planície], e em relação aos contos que aparecem antes e depois em Paisagem com Paisagem. A seção final aborda a questão da escala na literatura e especula sobre como a obra de Murnane, com seu foco em Melbourne, pode ser compreendida no Brasil.

Palavras-chave: Gerald Murnane, “The Battle of Acosta Nu”, Nova Austrália

Abstract: This article examines the story "The Battle of Acosta Nu", written by Australian author Gerald Murnane and appearing in his 1985 volume, Landscape with Landscape. Firstly, it examines the historical basis for the story - the Australian context of the 1890s and the founding of the New Australia colony in rural Paraguay - and gives an overview of Murnane's work in the 1980s. It then analyses "The Battle of Acosta $\mathrm{Nu}$ " in relation to Murnane's earlier novel, The Plains, and in relation to the stories that come before and after it in Landscape with Landscape. The final section deals with the issue of scale in the reading of literature, and speculates on how the Melbourne-focused scale of Murnane's work can be understood in a Brazilian context.

Keywords: Gerald Murnane, “The Battle of Acosta Nu”, New Australia

Eles tinham imaginado um lugar tão desolado e crianças tão solitárias que um leitor só poderia imaginar aquelas crianças se imaginando numa terra onde crianças se amontoavam em salas de aula olhando fotos de crianças ainda mais solitárias em terras desoladas.

Gerald Murnane, "A Batalha de Acosta Nu"1

\footnotetext{
${ }^{1}$ Todos os trechos citados foram traduzidos pelo presente autor.
} 
Em 1985, um escritor australiano, Gerald Murnane, publicou um livro chamado Landscape with Landscape [Paisagem com paisagem], um conjunto de seis contos interligados, dos quais um se chama "The Battle of Acosta Nu" [A batalha de Acosta $\mathrm{Nu}$ ], fazendo referência à batalha que aconteceu em 16 de agosto de 1869. Naquele dia, chamado de "Batalha de Campo Grande" pelos brasileiros e de "Batalla de Los Niños" pelos paraguaios, 20.000 soldados brasileiros e aliados lutaram contra 4.000 paraguaios, dos quais mais de 3.000 eram crianças. Sob as ordens do Conde d'Eu, mesmo os paraguaios que sobreviveram à batalha foram massacrados no final do dia. De uma população de 800.000 habitantes, a guerra deixou o Paraguai com apenas 150.000 mulheres, 14.000 homens e 81.000 crianças, mas Murnane não trata nem da batalha, nem da guerra, e sim de um dos seus possíveis resultados, gerações mais tarde. "A Batalha de Acosta Nu" é um reflexo excêntrico de um empreendimento ainda mais excêntrico, que levou quase 500 australianos a fundar a colônia de Nova Austrália no interior do Paraguai em 1893, numa tentativa (do ponto de visto dos colonos) de estabelecer uma utopia comunista e (do ponto de vista do governo paraguaio) de preencher o vácuo populacional deixado pela Guerra da Tríplice Aliança.

Os australianos não foram os primeiros. Em 1872, dois anos depois do fim da guerra, um grupo de 800 ingleses foi assentado cerca de 35 quilômetros ao sudeste de Assunção, mas eles não tinham experiência com a agricultura, nem com as condições locais: 162 morreram e os outros foram resgatados por uma sociedade benevolente de britânicos em Buenos Aires. Em 1881, o Congresso paraguaio passou uma lei autorizando o Governo a ceder terras públicas para colonização, e até o final da década pelo menos duas colônias alemãs foram fundadas. A primeira, San Bernardino, na margem do lago Ypacaraí, a 30 quilômetros de Assunção, se transformou num balneário para veranistas da capital; Nueva Germânia, projeto dos antissemitas Bernhard Förster e Elisabeth Förster-Nietzsche, fracassou na sua tentativa de mostrar para o mundo a superioridade ariana. Em 1892, foi a vez dos representantes da Associação da Nova Austrália que, não satisfeitos com as possibilidades nas províncias argentinas de Rio Negro, Chubut e Neuquén, chegaram em Assunção para negociar com o governo. Com a promessa de assentar 1.200 famílias em seis anos, eles receberam 187.000 hectares de terra fértil, ao leste da capital.

Nos dias de hoje, poucas pessoas na Austrália pensariam em sair do país para buscar uma vida melhor no Paraguai. Naqueles dias também. O teor do movimento 
trabalhista australiano sempre foi mais reformista que revolucionário, mas a conjuntura do início da década de 1890 levou muitos a perderem a paciência. Seca no interior, baixo preço da lã (principal produto de exportação e motor de toda a economia), depressão e desemprego nas cidades, quebra de bancos, conflitos entre proprietários e trabalhadores, uso de tropas para trazer trabalhadores "independentes" das cidades numa tentativa de desfazer os direitos conquistados pelos sindicatos. Um lado do movimento fundou o Partido Trabalhista, que segue até hoje como uma das principais forças políticas no país; outro fragmento buscou soluções mais extremas. Sob a liderança carismática do jornalista William Lane, o primeiro grupo de colonos chegou na Nova Austrália em 28 de setembro de 1893, unidos - pelo menos publicamente pelos princípios da Associação, uma mistura estranha de comunismo utópico, racismo britânico e abstemia.

Os princípios duraram pouco: muitos dos colonos estavam mais interessados em se dar bem do que na ideia de criar uma utopia igualitária. Os homens solteiros viam cada vez menos sentido na regra de não se misturarem com a população local, composta por uma enorme maioria de mulheres solteiras, e a bebida alcoólica sempre mantém o seu apelo. Em julho de 1894, com o rápido desmanche do projeto utópico, Lane e seus seguidores mais fiéis fundaram uma segunda colônia - Cosme - num outro terreno cedido pelo Governo paraguaio, criando assim um tipo de Novíssima Austrália, ainda mais pura e mais rígida que a meramente Nova (cabe lembrar que a própria Austrália só passou a existir como país com a federação das seis colônias britânicas no primeiro dia do século XX). Conforme os cálculos de Gavin Souter, que visitou o que sobrevivia das colônias em 1965 e publicou seu relato do episódio em A Peculiar People [Um povo peculiar], a população máxima de Cosme foi de 131 habitantes, e a da Nova Austrália, pouco mais que 200; o caráter australiano das duas logo se diluiu (SOUTER, 1991, 282).

O que sobrou da experiência? No mundo real, muito pouco: alguns sobrenomes, algumas palavras, uma pequena herança genética. $\mathrm{O}$ mais conhecido descendente dos colonos deve ser o premiado roteirista de histórias em quadrinhos, Robin Wood, nascido em Cosme em 1944. Numa entrevista de 2000, Wood afirma ter nascido "numa colônia socialista de australianos que vieram ao Paraguai, num lugar que até hoje não tem eletricidade, nem água encanada, nem nada" (ACCORSI). No mundo da literatura, existe a obra de Mary Gilmore, socialista, pacifista e poeta, que passou três anos e meio 
em Cosme, voltou para a Austrália e hoje em dia tem seu rosto estampado na cédula de dez dólares. Existe um romance de Michael Wilding, The Paraguayan Experiment [A experiência paraguaia], publicado em 1984, que oferece uma versão ficcionalizada da vida em Cosme. E existe "A Batalha de Acosta Nu”, de Gerald Murnane.

\section{Gerald Murnane e sua obra}

Gerald Murnane nasceu em Melbourne, em 1939, e tem passado quase a totalidade da sua vida no estado de Victoria, uma área menor que o Rio Grande do Sul. A tendência de sua ficção, porém, não é de se restringir a essa pequena região, e sim de imaginar o mundo a partir dela. Foi em 1982 que Murnane publicou a primeira das suas obras que não pode ser confundida com autobiografia: o romance The Plains [A planície], um tipo de ficção histórica que examina aquilo que existe através de uma descrição cuidadosa daquilo que poderia ter existido. Do mesmo modo que certos contos de Jorge Luis Borges são investigações filosóficas que se ambientam num tipo de sonho de Buenos Aires, um espaço que um leitor desavisado poderia confundir ou com a verdadeira Buenos Aires ou com uma cidade qualquer, A Planície é uma investigação filosófica que se ambienta num tipo de sonho do interior da Austrália. Todas as suas frases são perfeitamente compreensíveis, mas só o leitor com um conjunto específico de conhecimentos e de expectativas vai perceber com precisão o ângulo de desvio entre cada elemento, cada diálogo, cada conceito e seu equivalente na Austrália real.

Na década de 1890, a visão dominante da nacionalidade australiana tinha um viés fortemente rural que chegava a ver as cidades portuárias do litoral como essencialmente ligadas à cultura europeia e, portanto, a um passado prestes a ser superado. Uma versão daquela visão foi renovada como mito nacional no período após a Segunda Guerra Mundial e persiste de certa forma até o presente; A Planície se ambienta na década de 1970 de uma Austrália alternativa em que aquela relação de campo e cidade é simplesmente real, mas sem nunca chamar a atenção explicitamente para isso. É o leitor que tem que conhecer a realidade e o mito, fazer os cálculos e acertar nos detalhes.

Três anos mais tarde, foi a vez de Paisagem com paisagem, que contém "A Batalha de Acosta Nu". É um ciclo de seis contos, interligados de tal forma que o 
narrador-personagem de cada conto afirma ser o escritor do conto seguinte e, portanto, acaba sendo uma invenção criada pelo narrador-personagem do conto anterior. Todos os narradores são homens de meia-idade, patologicamente solitários, que se esforçam para encontrar sentido estético na sua própria solidão. Desse jeito, além de fazer sentido como obra de ficção nos seus próprios termos, cada um dos contos também funciona como contexto de produção de outra obra, lançando luz sobre o conto seguinte, e como obra escrita por um personagem que procura entender a sua própria situação, lançando luz sobre o conto anterior. Temos, assim, três visões sobre cada conto: a do próprio narrador do conto em questão, a do narrador anterior, que o criou, e a do narrador seguinte, que foi criado por ele.

Aquilo que A Planície elabora uma vez - a relação psicológica entre um narrador de Melbourne e um sistema que interliga paisagem e estado de espírito -, Paisagem com paisagem trabalha recursivamente, de tal maneira que o chão de um conto se sustenta apenas na psicologia do narrador do conto anterior. $\mathrm{O}$ romance seguinte, Inland [Interior] (1988), estabelece um tipo de isonomia entre as planícies da Hungria, dos Estados Unidos e da Austrália; o narrador parece transitar entre mundos diferentes, deixando o leitor na posição de tentar decidir se um ou outro é mais real que os demais. As leituras que levaram Murnane a tratar da Hungria no romance também o levaram - aos 56 anos de idade - a aprender húngaro.

Do mesmo jeito que o Aleph de Jorge Luis Borges permite enxergar o mundo no porão de uma casa em Buenos Aires, a obra de Murnane nos oferece a possibilidade de enxergar o mundo em relação a Melbourne. O Paraguai de "A Batalha de Acosta Nu" é visto a partir de Melbourne, não num Aleph, talvez, mas num copo de cerveja.

\section{2 "A Batalha de Acosta Nu" e A Planície}

“A Batalha de Acosta Nu", então, é um conto de umas 50 páginas, narrado por um homem que mora no Paraguai, mas que (por causa de alguns comentários feitos pelo pai antes de morrer) acredita ser descendente de colonos australianos e, portanto, não paraguaio. Sua tarefa mais importante na vida seria a de se manter fiel à Austrália que seus avós deixaram, uma Austrália que ele conhece apenas através de leituras e de sua própria imaginação. Ele imagina que essa condição de australiano seja uma característica que ele compartilha com apenas um pequeno número de habitantes do 
Paraguai, e passa a juventude ao mesmo tempo querendo encontrar uma australiana da sua idade e temendo revelar indevidamente a sua natureza oculta. Acaba casando com uma mulher que, conforme ele, é australiana sem saber; eles têm um filho e uma filha; a esposa se mostra irremediavelmente paraguaia; o narrador decide por fim que a sua única herança é o filho, que compartilharia a condição de australiano. O homem se dedica às tarefas de imaginar a Austrália e de repassar essa Austrália imaginada ao seu filho, apesar do pouco interesse que este parece mostrar no assunto. Ele se afasta do cotidiano paraguaio, lê e escreve; entre outras coisas, escreve o próximo conto no livro, "A Quieter Place Than Clun" [Um lugar mais tranquilo que Clun].

Acontece que o filho fica doente: o narrador, acreditando que um menino australiano não deveria se submeter aos procedimentos da medicina paraguaia, se recusa a buscar ajuda profissional, até que sua esposa insiste e o menino é levado ao hospital, onde acaba morrendo. Assim, o narrador percebe que seu filho morreu lutando bravamente, insanamente, como os menino-soldados da Batalha de Acosta $\mathrm{Nu}$, e que sofreu a mesma derrota; percebe que seu filho morreu assim em solo paraguaio e que era, portanto, paraguaio; e percebe que, se seu filho era paraguaio, ele também deve ser paraguaio, e não australiano. Essa percepção não traz, no entanto, uma sensação de pertencimento. Muito pelo contrário: no movimento final do conto, o narrador mantém sua sensação de isolamento e conclui que, se ele é paraguaio, todas as outras pessoas que ele conhece devem ser australianas, e o país que ele conhece apenas através da imaginação deve ser o Paraguai.

A irracionalidade dessa última conclusão age contra qualquer esforço do leitor em estabelecer algum tipo de paralelo entre a relação Paraguai-Austrália no conto e qualquer relação entre nações ou lugares no mundo real, mas mesmo assim o conto parece convidar justamente a esse tipo de esforço. Na primeira frase, o narrador afirma estar na cidade de Melbourne, mas não na Austrália; é no segundo parágrafo que ele revela que Melbourne fica no Paraguai, mas o Paraguai do conto não é (e não faz nenhum esforço de ser) uma representação do Paraguai real. Pelo contrário, o Paraguai do conto é descrito sempre em termos que sugerem imagens típicas da Austrália, tanto em termos da vegetação quanto dos costumes: o mutirão na escola pública, por exemplo, é tão evidentemente uma cena australiana que parece um despropósito especular se a mesma cena também poderia acontecer no Paraguai. A vegetação no conto é australiana: "ironbarks" (MURNANE, 2003, p. 78) são um tipo de eucalipto, e 
“wattle trees" (MURNANE, 2003, p. 82) são a acácia que aparece no brasão da Austrália. Os próprios "paraguaios típicos”, que são os vizinhos do narrador, parecem ser os australianos típicos da época: "a casa não tinha nenhum livro e eles nunca ouviram falar da Austrália, mas gostavam do desafio de tarefas práticas" (MURNANE, 2003, p. 84). O narrador detecta na literatura do seu Paraguai "uma saudade inexpressável por uma terra que paraguaio nenhum jamais entraria” (MURNANE, 2003, p. 61), e se pergunta "se, na verdade, o Paraguai pode corretamente ser chamado de um país com um modo de vida, ou se todos os paraguaios se imaginaram como exilados de um país vasto e maravilhoso: a terra que eles enxergaram através da abertura estreita das suas televisões” (MURNANE, 2003, p. 74). A Austrália da década de 1980 não deve ser o único lugar em que as pessoas sentiam a necessidade de buscar uma sensação de completude nos produtos culturais de outras terras, mas se o leitor lesse "Austrália" e "australianos" cada vez que o conto mencionasse "Paraguai" e "paraguaios", ele dificilmente encontraria qualquer surpresa.

Desde o início do conto, a relação entre o Paraguai e a Austrália é estabelecida em termos paradoxais. O narrador começa assim: "Eu estava numa colina ao nordeste de Melbourne, olhando por cima dos bairros ondulados, em direção à Serra de Kinglake, e quase acreditei que eu estava realmente na Austrália” (MURNANE, 2003, p. 56). É apenas no segundo parágrafo que se descobre que Melbourne fica no Paraguai, mas a primeira frase já revela que não fica na Austrália. Para quem conhece a obra anterior de Murnane, esse paradoxo - a representação de um mundo que é e não é aquilo que conhecemos como a Austrália - pode lembrar a abertura de A Planície, em que o narrador parte de Melbourne para o interior e nem consegue identificar o momento em que ele "não está mais na Austrália" (MURNANE, 2000, p. 3). Em $A$ Planície, Melbourne fica na Austrália, e a autenticidade reside no interior, "cercada pela Austrália" (MURNANE, 2000, p. 8); em “A Batalha de Acosta Nu”, Melbourne fica num Paraguai que mais parece a Austrália, e a autenticidade reside no exterior, numa Austrália imaginada que tem sempre uma aura de irrealidade. Em A Planície, a paisagem parece uma forma idealizada do próprio interior do continente australiano, enquanto a geografia da Austrália de "A Batalha de Acosta Nu" parece uma alucinação feita de fragmentos de tudo que possa parecer grandioso: de "planaltos congelados" e um "mar de dentro" (MURNANE, 2003, p. 59), de "pradarias imensas" e "dez mil lagos" (MURNANE, 2003, p. 65), de "pregas de cordilheira" e "arquipélagos 
incontáveis" (MURNANE, 2003, p. 66), de "selvas" e "savanas" (MURNANE, 2003, p. 82), de seu “Grande Vale do Rift” e seus “Grandes Lagos” (MURNANE, 2003, p. 86). Em A Planície, a conquista do interior parece ter sido um ato de entrar num espaço vazio, sem população indígena, sem nenhum projeto colonial rival, e sem significado até ser enxergado pelo colonizador: "aquilo que, a princípio, parecia totalmente plano e indiferenciado acabou revelando inúmeras variações de paisagem e uma abundância de fauna furtiva" (MURNANE, 2000, p. 12). A escolha do Paraguai como ponto de comparação em "A Batalha de Acosta Nu" realça não apenas a história de conflito entre impérios rivais (espanhol, jesuíta, português), mas também uma profunda mestiçagem étnica e cultural: o próprio narrador fala "castelhano idiomático e guarani" (MURNANE, 2003, p. 57).

Se a geografia da Austrália imaginada não passa de uma colcha de retalhos, sua cultura não é menos alheia à realidade do país em que Murnane escreveu o conto: o narrador fala na "tradição rica e excêntrica" da "filosofia e teologia australianas" (MURNANE, 2003, p. 61) e sugere que um médico no Paraguai teria "o tipo de influência que um escritor de ensaios teria na Austrália" (MURNANE, 2003, p. 75). Essa imagem de um país culto e sutil, um lugar de autenticidade cultural localizado ou no interior ou no exterior, mas sempre a uma certa distância de Melbourne, também forma o pano de fundo de A Planície. Juntando as representações da paisagem e da cultura no romance e no conto, o resultado parece refletir a dificuldade de tentar construir uma identidade cultural, não apenas na Austrália, mas em qualquer nação do Novo Mundo que precisa esquecer do fato de ter nascido de uma cultura do outro lado do mar, transplantada numa terra que foi roubada de uma população indígena massacrada. O narrador de A Planície busca a completude e a autenticidade no interior do seu próprio país, mas num interior higienizado, sem a violência da história colonial; o narrador de "A Batalha de Acosta Nu" busca a completude e a autenticidade no exterior, na sua origem colonial, num lugar para o qual ele sabe que não tem como voltar, porque "fazer isso seria arriscar o impensável: descobrir no fim que a Austrália não tem a amplitude para abarcar nossa ideia dela" (MURNANE, 2003, p. 75). O Paraguai (ou a Nova Austrália) é o único lugar que, historicamente, proporciona a possibilidade dessa visão da Austrália, que permite que o narrador olhe para a Austrália do mesmo jeito que a Austrália olha para a Inglaterra ou para os Estados Unidos, que vira ao avesso o espelho torto de centro e periferia. Mesmo assim, muitos jovens 
australianos devem ter experimentado algo da mesma sensação ao desembarcar em Londres e descobrir que a Inglaterra não é tudo que se falou, mas apenas um lugar em que outras pessoas seguem as suas rotinas cotidianas.

Os velhos centros culturais do ocidente - Londres, Paris, Viena, Roma - vivem no imaginário de milhões de pessoas em outros continentes; Melbourne, não. Num dos pensamentos mais complexos de "A Batalha de Acosta Nu", o narrador procura analisar a sensação de viver num lugar que não é o foco de atenção de pessoas que vivem longe dele. Ao pensar sobre como ele deve criar seu filho, morando no Paraguai mas sendo secretamente australiano, ele diz:

\begin{abstract}
Eu não queria que o meu filho achasse que as coisas no Paraguai fossem de alguma maneira menos reais, ou que à própria terra faltasse solidez porque, diferente da Austrália, nunca foi sonhada ou imaginada por pessoas em lugares distantes. Na infância, eu já tinha percebido que qualquer paraguaio, tão logo que descobrisse que seu país era apenas um entre muitos no mundo, colocado sempre lá na margem dos mapas convencionais, nunca mais falava do Paraguai como um lugar em que coisas interessantes pudessem acontecer. (MURNANE, 2003, p. 76)
\end{abstract}

Nas páginas seguintes, ele analisa a possibilidade (uma teoria desenvolvida na juventude) de a Nova Austrália ser não uma imitação da Austrália real, mas uma tentativa de chegar mais perto da essência da Austrália, mais perto do que seria possível na Austrália original. Conforme essa lógica, a essência da Austrália ficaria não no outro lado do mar, mas escondida em algum lugar no próprio Paraguai; o narrador não consegue aceitar essa possibilidade, e volta a ver o Paraguai como apenas "a terra onde eu nasci e que me decepcionou" (MURNANE, 2003, p. 77). Ele lembra, apesar dessa decisão, que "me imaginava propositalmente como paraguaio sempre que ouvia as outras crianças reclamarem de nunca encontrar no mato em torno da sua cidade provincial as aventuras que crianças de outras terras desfrutariam" (MURNANE, 2003, p. 78), e o que segue é uma das imagens cruciais do conto. Nos livros da escola, o narrador-menino encontrava histórias e relatos ambientadas ou em países importantes, ou em terras estranhas e remotas, mas nunca no Paraguai ou na Austrália. Ele sentia pena do Paraguai e jurava que não ia esquecer do país quando chegasse na Austrália, mas que ia "imaginá-lo como paraguaio algum conseguiria imaginar, e tornar toleráveis as tardes compridas de um menino como eu, que poderia ter suportado a poeira e o silêncio do quintal se ele soubesse que estava dentro dos limites amplos dos pensamentos de alguém" (MURNANE, 2003, p. 79). Com esses sentimentos, o narrador parece representar o efeito de se encontrar na periferia da cultura ocidental: não é que a 
vida ou mesmo a produção cultural sejam realmente inferiores ou menos complexas que aquelas dos lugares percebidos como centrais, e sim a própria sensação de desequilíbrio: nós olhamos para o centro, mas o centro não olha para nós.

Essa sensação de ser periférico não é apenas uma questão da relação entre o Novo Mundo e o Velho, e fica clara com o próximo passo do argumento, quando o narrador-menino encontra uma foto de três crianças, vestidas no estilo de uma geração anterior, com a legenda "Criancinhas numa fazenda de criação de ovelhas no longínquo Paraguai" (MURNANE, 2003, p. 79). Diz o narrador:

\begin{abstract}
Mas a foto das criancinhas na fazenda de criação de ovelhas me alertou que algo estava errado nos países onde se escreviam livros. Nunca vi, e nunca imaginei que ia ver, nenhuma criança no Paraguai vestida como as crianças na foto. A palavra 'fazenda' não era usada no Paraguai. As pessoas que estavam escrevendo e lendo sobre uma terra chamada Paraguai tinham conjeturado livremente demais. (MURNANE, 2003, p. 79)
\end{abstract}

No único momento em que o menino encontra algo do seu mundo refletido no mundo dos livros, ele percebe que o reflexo é tão distorcido que serve não para enriquecer, mas para anular a sua existência. A palavra traduzida como "fazenda" é ranch, usada nos Estados Unidos, mas nunca na Austrália, o que sugere que a relação entre periferia e centro pode existir não apenas com a velha capital Imperial, mas também, por exemplo, entre Melbourne e Nova York, ou entre Porto Alegre e São Paulo.

Para o narrador-menino, ser imaginado desse jeito não torna suportável seu dia na escola poeirenta; muito pelo contrário, ele se sente jogado num redemoinho de autonegação, na densa frase citada na epígrafe: "Eles tinham imaginado um lugar tão desolado e crianças tão solitárias que um leitor só poderia imaginar aquelas crianças se imaginando numa terra onde crianças se amontoavam em salas de aula olhando fotos de crianças ainda mais solitárias em terras desoladas" (MURNANE, 2003, p. 79). Se as crianças na foto não poderiam estar no Paraguai, ele se pergunta onde exatamente eles estavam, e começa a imaginar uma terra sem nome, "uma terra-entre-as-terras" de "céus cinzentos e horizonte impreciso" (MURNANE, 2003, p. 80); é para essa imagem que o narrador retorna na hora da morte de seu filho. Ele vê o filho "vagueando na terra sem nome, na terra-entre-as-terras, o mesmo lugar cinzento onde uma vez três crianças tinham vagueado e sido confundidas por criancinhas numa fazenda de criação de ovelhas no longínquo Paraguai” (MURNANE, 2003, p. 94), e é nesse momento que o 
médico chega com a notícia de que o filho "tinha lutado que coragem extraordinária, mas que agora estava morto" (MURNANE, 2003, p. 95).

Essa imagem - da luta valente de uma criança até a morte - leva o narrador de volta à ideia da Batalha de Acosta $\mathrm{Nu}$, mencionada pela primeira vez no dia em que o filho adoeceu. Naquele momento, ele tinha falado do "gesto suicida de resistência" e dos mortos paraguaios, "meninos, alguns de apenas dez anos, ainda segurando como armas paus afiados ou pedras ou pedaços de vidro ou até punhados de terra", e se consolado com o fato de que "nenhum australiano jamais teria que sofrer daquele jeito pelo país" (MURNANE, 2003, p. 80). Quando o narrador entende que seu filho morreu, ele afirma estar "finalmente no lugar que eu tinha temido desde o dia em que me tornei pai de um menino na terra de Paraguai. Eu estava no campo de batalha de Acosta $\mathrm{Nu}$, procurando entre os criança-soldados morrendo ou já mortos pelo corpo mutilado do meu único filho" (MURNANE, 2003, p. 96). É isso que, conforme o pensamento anterior, nenhum australiano teria que sofrer, mas é justamente isso que milhares de Aborígenes sofreram quando também morreram defendendo sua terra, armados com paus e pedras, em atos que poderiam ser descritos como gestos suicidas de resistência. Esse apagamento da experiência indígena não é mera idiossincrasia de um homem desequilibrado: é um dos pontos de partida da própria ideia de ser australiano, e talvez do frágil conceito de nação no Novo Mundo. Sem poder recorrer a nenhum passado confiável, afastado tanto da fonte europeia da cultura ocidental quanto do conhecimento Aborígine da terra australiana, o narrador gira de uma interpretação insana de sua vida para outra: de um australiano cercado de paraguaios, ele se transforma instantaneamente em um paraguaio cercado por australianos.

\section{3 "A Batalha de Acosta Nu" e Paisagem com paisagem}

Dos seis contos de Paisagem com paisagem, apenas "A Batalha de Acosta Nu" tinha sido publicado antes de aparecer no livro; parece fazer sentido examinar os contos que aparecem antes e depois como sendo construídos em relação a esse e, portanto, como oferecendo alguma ajuda na sua interpretação. "A Batalha de Acosta Nu" é narrado no passado - o narrador sabe o desfecho antes de começar a narrar -, mas o conto seguinte, "Um Lugar Mais Tranquilo que Clun”, foi escrito por esse narrador antes da morte do filho, antes de ele descobrir que não é e nunca foi australiano. $\mathrm{O}$ ato 
de escrever "Um Lugar Mais Tranquilo que Clun" é, portanto, anterior ao ato de narrar "A Batalha de Acosta Nu". O narrador o descreve assim:

\begin{abstract}
$\mathrm{Na}$ verdade, eu já tinha pensado, em momentos de desespero, em abandonar a minha busca pela Austrália e me compensar com a tarefa permanente de ler e de escrever ficção. Certo tipo de romance sempre me parecia como um capítulo da história da Austrália; muitos personagens de ficção pareciam pensar como australianos; e às vezes as últimas páginas de um romance me tocavam como o vento de uma pátria perdida. Num desses humores, eu tinha chegado ao ponto de escrever alguns rascunhos de ficção. "Um Lugar Mais Tranquilo que Clun" era uma história tal como um australiano poderia ter escrito se tivesse sido obrigado a parar de pensar e de escrever sobre a Austrália. (MURNANE, 2003, p. 87)
\end{abstract}

O narrador de "Um Lugar Mais Tranquilo que Clun" - imaginado por um homem que mora em Melbourne, Paraguai, e que acredita ser australiano - é um homem que mora em Melbourne, Austrália, e procura resolver uma série de oposições entre estados de ser, cores e paisagens. Num primeiro momento, como um jovem católico no final da década de 1950, a oposição é entre a ortodoxia e a rebeldia: "Se a cor da ortodoxia era o branco-prateado transluzente de uma alma pura, então a cor da rebeldia era a cor da pele" (MURNANE, 2003, p. 100). Logo, essa oposição se transforma em duas cenas recorrentes, que são visões do futuro: na primeira, o narrador se via como seminarista, olhando pela janela da biblioteca, "uma chuva de teologia prateada encharcando a minha alma, enquanto a chuva lá fora varria o gramado" (MURNANE, 2003, p. 100); na segunda, ele se via como aluno de psicologia ou filosofia na Universidade de Melbourne, "sem nenhuma obrigação a não ser obedecer os impulsos dos nervos enfeixados embaixo da minha pele" (MURNANE, 2003, p. 101). Lembramos que a filosofia e a teologia, aqui opostas, fazem parte da tradição que o narrador de "A Batalha de Acosta Nu" imagina para a cultura australiana. Na verdade, o narrador não consegue passar na prova para nenhuma das duas instituições; ele trabalha no serviço público, lê, faz anotações, escreve alguma poesia e foge da dualidade por um tempo, sonhando com as paisagens mais variadas.

Num segundo passo, a dualidade de paisagens e de estados de ser passa a se identificar com duas imagens nos velhos números de National Geographic que o narrador encontra num sebo. No lado da alma, ele elege "um morro coberto de mata sem folhas em Kentucky" (MURNANE, 2003, p. 102), que ele identifica com a ideia de um mosteiro cisterciense; no lado da pele, ele escolhe uma foto da Carolina do Norte, "um lugar protegido entre as dunas, com um céu azul emoldurado por nuvens delicadas", em que uma moça de bermudas deita, lendo (MURNANE, 2003, p. 103). A 
dualidade na mente do narrador (entre a alma e os nervos, ou entre o branco-prateado e a cor da pele, ou entre o seminário e a universidade) se transfere de Melbourne para a costa leste dos Estados Unidos, sem nenhuma mudança essencial. Para o escritor de "Um Lugar Mais Tranquilo que Clun" - o áustralo-paraguaio que é o narrador de "A Batalha de Acosta Nu" - não parece fazer nenhuma diferença ficar dividido entre duas vistas em Melbourne ou outras duas nos Estados Unidos.

O segundo momento de dualismo também se resolve com a literatura: o narrador vê uma mulher comprando um romance de Thomas Hardy numa livraria: "Eu queria perder de vista a minha própria paisagem instável e olhar apenas a paisagem dessa mulher. Decidi que apaixonar-se por uma mulher nada mais era do que querer urgentemente enxergar a paisagem dela" (MURNANE, 2003, p. 104). A capa do livro é de um verde tranquilo, que passa a ser a resolução da oposição entre as cores da alma e da pele; o narrador procura se esvaziar de qualquer paisagem australiana (ou americana) e se identificar com aquilo que chama de "paisagem literária"; ele resolve abandonar tanto a teologia quanto a filosofia e se dedicar à poesia: "Nas paisagens literárias, eu não ia nem salvar, nem perder a minha alma" (MURNANE, 2003, p. 108). Da ficção de Hardy, o narrador passa à poesia de A. E. Housman, autor do poema de qual se tirou o título do conto. O autor passa por outra reorganização das suas paisagens e decide que, ao invés de olhar para o mundo a partir de Melbourne, ele vai assumir a visão de Housman: "Todos os lugares que eu já tinha olhado ficavam para além de Shropshire, como esse condado deveria aparecer a um poeta em Londres, olhando ao oeste no fim da tarde" (MURNANE, 2003, p. 110). Se esvaziar de qualquer paisagem concreta para se identificar com a "paisagem literária" parece ser o equivalente de o homem do Paraguai parar de pensar sobre a Austrália e escrever ficção, mas a paisagem literária logo se concretiza, e justamente como uma paisagem na Inglaterra, origem colonial da cultura de Melbourne, Austrália. O narrador que achava que poderia esquecer do local para entrar abstratamente na "literatura mundial" acaba reproduzindo a primazia do centro sobre a periferia.

Mais tarde, o narrador passa a depender menos de imagens de paisagens, sejam elas reais ou imaginadas; ele lê Jung, começa a se imaginar como uma psique "que brilha como um diagrama, complexo e multicolorido" (MURNANE, 2003, p. 125), e abandona a poesia, dedicando-se à complexidade do romance. Depois disso, em outro momento, ele se identifica com a imaginação, "não como algo com qualquer cor ou 
formato, mas como um espaço amplo o suficiente para um sistema de estradas que cruzariam nele, para depois divergir e depois talvez se encontrar de novo por meio de bifurcações e desvios estranhos" (MURNANE, 2003, p. 132). Esse narrador, invenção do narrador paraguaio-australiano que "tinha sido obrigado a parar de pensar e de escrever sobre a Austrália”, parece ter ido para além das paisagens locais (de Melbourne), estrangeiras (americanas, inglesas), ou literárias (de Hardy, de Housman), para um espaço abstrato e não localizável. Seria isso a vitória do universal sobre o local? Não, porque o último momento do conto é um tipo de volta às origens:

\begin{abstract}
O meu lugar era Melbourne e o interior ao norte e ao oeste. (Nunca tinha estado em outro lugar; o meu cabelo estava ficando grisalho, e eu nunca tinha atravessado a divisa do estado de Victória.) Eu não deixaria um professor de uma língua morta me menosprezar, como se fosse obrigação minha como homem de cultura conhecer os caminhos da Universidade de Oxford, e obrigação dele nem saber onde ficava Melbourne. (MURNANE, 2003, 136)
\end{abstract}

Uma volta às origens, ou pelo menos um reconhecimento de que as origens não podem ser apagadas com um gesto universalizante, porque os centros e suas periferias existem, querendo ou não.

O que acontece quando um escritor de Melbourne, Paraguai, é forçado a parar de pensar sobre a Austrália, ou sobre a versão da Austrália imaginada na década de 1890 e reforçada como mito nacional na década de 1950? O narrador de "A Batalha de Acosta Nu" parece abandonar o conceito de nação: o que ele conhece, concretamente, é a sua cidade, e ele escreve um conto que tem Melbourne sempre como ponto de partida, mas vai aumentando e diminuindo o alcance da sua visão, numa tentativa de tornar significativa uma vida que se passou trabalhando, lendo e pensando numa cidade no extremo sul do mundo anglófono. Mas o próprio conto “A Batalha de Acosta Nu”, seu narrador e a cidade de Melbourne, Paraguai, são invenções de outro homem, o narrador de "Sipping the Essence" [Sorver a essência]. Ele também mora em Melbourne (Austrália), e enxerga o mundo a partir daquele foco. Para esse narrador, a paisagem que faz o contraponto à cidade e à vida dele é o estado tropical de Queensland (na verdade, Queensland não é de todo tropical: sua costa leste corresponde em latitude ao litoral dos estados brasileiros de Sergipe, Bahia, Espírito Santo, Rio de Janeiro, São Paulo, Paraná e Santa Catarina. Melbourne, por sua vez, fica mais ou menos na latitude de Bahia Blanca, na Argentina).

O conto abre em dezembro de 1959, quando o narrador tem uns vinte anos e acredita não pertencer a Victoria, e sim "ser destinado a desfrutar, quando for a hora, os 
prazeres refinados e duradouros de Queensland" (MURNANE, 2003, p. 23), estado que ele conhece apenas de fotos. Esse narrador lê Kerouac e (depois de beber o suficiente) vê "uma aura poética em volta do meu Queensland-Califórnia". Seu amigo Durkin ouve jazz; quando eles se interessam por uma moça chamada Carolyn, o narrador imagina os dois de uma maneira que espelha o Sul e o Norte da Austrália no Oeste e no Leste dos Estados Unidos; ela teria que escolher entre

\footnotetext{
o homem elegantemente vestido que se via posado na frente das colinas formosas da Península de Mornington [ao sul de Melbourne] ou das mansões cobertas de hera da Nova Inglaterra, e o homem tosco e desajeitado que já estava explorando na sua poesia a vegetação emaranhada de Queensland, ou atravessando o Iowa plano ou o Nebraska poeirento. (MURNANE, 2003, p. 28)
}

Na primeira noite em que o narrador sai com Carolyn, ele começa a imaginar a possibilidade de não ir para Queensland fisicamente, mas de ficar em Melbourne, casar com ela e "escrever uma epopeia ambientada num Queensland imaginário, onde lugares mais estranhos que Banana ou Barcaldine poderiam estar me esperando" (MURNANE, 2003, p. 34). Na verdade, Carolyn acaba casando com Durkin. Alguns anos depois, o narrador - ainda solteiro, escrevendo um pouco de poesia, bebendo cada vez mais - se contenta com "um Queensland que eu poderia visitar sem deixar a minha mesa de trabalho. Mesmo quando eu mal conseguia enxergar o contorno do lugar, eu achava que Carolyn e Durkin provavelmente me vissem já morando num Queensland estranho e metafórico" (MURNANE, 2003, p. 43). Mais tarde ainda, quando o narrador está prestes a se casar com uma mulher mais jovem, ele pensa nas tardes de sábado que vai passar no jardim, em que "eu levantaria o meu copo na luz da tarde e ainda enxergaria nele um tipo de Queensland" (MURNANE, 2003, p. 49).

Esse narrador de Melbourne, Austrália perde Queensland (um estado que ele nunca visitou) do mesmo jeito que o narrador de Melbourne, Paraguai, perde a Austrália (um país que ele também nunca visitou), e essa equivalência imaginária entre Estado e País é reforçada em dois momentos em "Sorver a essência", ambos ligados ao desejo de escrever. Quando o narrador pensa em escrever uma epopeia, ele se descreve como alguém que "pertence a outro país", referindo-se a Queensland (MURNANE, 2003, p. 34). A palavra usada, country, pode significar um país no sentido geopolítico, ou algo mais vago, mais afetivo, como "terra", mas não é sinônimo comum de "Estado". Bem no final do conto, ao descrever uma conversa com Durkin, o narrador diz: "Eu tinha terminado uma história sobre os 'Australianos Novos', os homens de Queensland que 
foram ao Paraguai para fundar um país de sonhos. Parece que eu tentei fazer ele ler o manuscrito, porque estava lá na mesa na manhã seguinte: 'A Batalha de Acosta Nu"” (MURNANE, 2003, p. 54). O movimento que levou à fundação da Nova Austrália começou em Queensland, mas certamente não foram apenas homens de Queensland que fizeram a viagem. Eles se chamavam de australianos, mas o próprio termo "australiano" não tinha significado político na época, porque as seis colônias britânicas se federariam para formar o país apenas em 1901 (o que quer dizer que a colônia de Nova Austrália existia - e já tinha quase deixado de existir - antes do país Austrália: os "Australianos Novos" estavam de luto por uma nação que tinha morrido antes de poder nascer). Para o narrador de "Sorver a essência", a Nova Austrália é um tipo de Novo Queensland. Assim, o Paraguai do narrador de "A Batalha de Acosta Nu", que a princípio parecia uma versão ficcionalizada da Austrália real, acaba sendo uma versão ficcionalizada de um Queensland imaginado. A nação australiana não parece existir nem como sonho nessas ficções de homens que imaginam o mundo a partir de Melbourne.

\section{Melbourne, Paraguai, e a escala da literatura}

A ideia de uma literatura realmente "nacional" - capaz de englobar a totalidade de uma nação e de se manter nitidamente separada de qualquer outra - talvez fizesse algum sentido abstrato na Europa do século XIX, com o seu mosaico de idiomas lutando por espaço, mas não é essa a situação no Novo Mundo, onde se escreve em línguas importadas e dentro de uma tradição que tem as suas raízes no outro lado do oceano. A literatura escrita em inglês na Austrália se conecta com o mundo anglófono e com o mundo ocidental de uma maneira muito particular; a literatura escrita em português no Brasil se conecta com o mundo lusófono e com o mundo ocidental de outra maneira, igualmente particular, mas muito diferente. Como podemos compreender seus possíveis paralelos?

No artigo "Does Writing Matter?" [Escrever importa?], Richard Flanagan usa Franz Kafka como um exemplo da fraqueza do conceito da literatura nacional: "Talvez suas histórias de alienação, de culpa, de não ser o que se parece, não pudessem ser escritas a não ser por um judeu falante de alemão numa cidade católica e eslávica, como Praga, mas o que isso faz de Kafka - alemão, judeu, tcheco, eslavo - talvez não importe" (FLANAGAN). Tratar "Sorver a essência" simplesmente como "literatura 
australiana" seria ignorar a diferença entre sua representação relativamente concreta de Melbourne e de Victoria, e sua visão fantasiosa de Queensland. Mas se a velha exigência de nacionalidade não serve mais, qual moldura devemos usar para ler a ficção? No artigo "National Literatures, Scale and the Problem of the World" [Literaturas nacionais, escala e o problema do mundo], Robert Dixon critica a sugestão de que a resposta seja a chamada "literatura mundial". Ele pergunta:

\begin{abstract}
Qual é a escala adequada para o estudo da literatura? Ou, em outras palavras, onde é que a literatura se localiza? Seria desejável ou mesmo possível estudar um texto ou o fenômeno da literatura em geral numa escala mundial? Quais seriam as consequências de abordar uma literatura nacional, como a australiana, ou a literatura de uma cidade como Melbourne ou Sydney na escala "do mundo"? Os textos convidam à leitura em escalas diferentes? Num sentido um pouco diferente da palavra "escala", quais são as consequências em termos do grau de resolução ou de precisão que poderíamos alcançar dessa perspectiva? Se um crítico estadunidense, por exemplo, lê um romance australiano como "literatura mundial", será que ele ou ela vai acertar nos detalhes? (DIXON, 2015, p. 1)
\end{abstract}

A obra de Murnane se localiza muito fortemente em Melbourne, mas pede para ser lida numa escala capaz de abranger uma série de outros lugares, mais ou menos distantes, mais ou menos fantasiosos, com as quais Melbourne é justaposta: o norte tropical da Austrália, as rodovias dos Estados Unidos, as planícies da Hungria, o interior do Paraguai. Mas o nosso problema - nós, leitores de Murnane no Brasil - não é apenas de escala, mas de duas escalas diferentes. Dixon imagina um crítico estadunidense lendo um romance australiano, ambos dentro do mundo anglófono; se um crítico brasileiro lê "A Batalha de Acosta Nu" como "literatura mundial", quais são os detalhes que ele ou ela teria que acertar?

Eu sou de Sydney e moro em Porto Alegre. Como Sydney, Porto Alegre é uma capital que tem seu núcleo colado na água, sem muito espaço plano, que cresceu de maneira algo aleatória, guiada mais pela topografia do que pelo planejamento, e que fica no segundo nível de cidades no universo do seu idioma. No nível acima de Sydney tem a dupla Londres e Nova York: a velha capital Imperial e a nova capital do capital; acima de Porto Alegre há a velha capital Imperial, Rio de Janeiro, e a nova capital do capital, São Paulo. Melbourne já é outra coisa: mais ao sul, logo mais fria; construída ao lado de um rio, em torno de um centro plano e quadrangular; rival de Sydney em termos de riqueza no século XIX por causa da exportação de ouro; hoje menor que Sydney, mas ainda considerada mais culta. Substituindo o charque pelo ouro, o equivalente no cenário sul-rio-grandense seria Pelotas. Imagino, então, a leitura da obra de Murnane 
como se ele fosse pelotense, como se toda a sua ficção colocasse Pelotas como ponto focal de uma visão do mundo.

Em A Planície, o Murnane pelotense estaria descrevendo uma versão ironicamente mitificada do pampa, com a diferença crucial de que o pampa já é oficialmente mitificado na cultura do Rio Grande do Sul. O romance australiano recupera um momento em que a cultura do interior era muito valorizada, e projeta um presente alternativo que pressupõe a continuação daquela valorização. Num Rio Grande do Sul em que até a capital comemora o dia da sua derrota pelas forças da oligarquia rural, as ironias do romance do nosso pelotense teriam que ser bem outras.

Na versão pelotense de "Sorver a essência", a cidade teria que ser vista em relação a uma versão imaginada do Brasil tropical, do Nordeste, o que implica uma relação bem diferente. Sydney começou em 1788 como uma prisão, e Brisbane, capital de Queensland, foi fundada uma geração depois para prisioneiros vistos como perigosos demais para ficar em Sydney; Melbourne, por sua vez, é a maior cidade na parte da Austrália que foi fundada por colonos livres. Há, sim, uma diferença importante entre essas duas partes da Austrália, mas não em termos étnicos; não há nenhum movimento racista que queira separar o sul da Austrália do Norte, ou que diga "Victoria é o meu país”. Para esse conto, também precisamos de um equivalente para a obra de Kerouac e para a visão dos Estados Unidos que ela proporciona. O escritor pelotense encontraria alguma imagem de liberdade-na-estrada em alguma obra brasileira? Existe algum romance do interior de São Paulo, ou talvez do Centro-Oeste, que ele possa usar para construir sua visão do Nordeste, da mesma maneira que o narrador de Murnane usa Kerouac para construir sua visão de Queensland? Tratar o Rio Grande do Sul como equivalente da Austrália na escala dos mundos lusófono e anglófono sugere que se identifique o interior dos Estados Unidos com outro trecho do Brasil, mas isso contradiz a escala física dos dois países. A distância de Pelotas para o Nordeste é parecida com aquela de Melbourne para Queensland, mas a distância intercontinental e interhemisférica até os EUA não pode ser encurtada para o trajeto miúdo entre Pelotas e o Planalto Central. Talvez um equivalente melhor seria os Diários de Motocicleta de Ernesto Guevara, só que sem a Revolução Cubana como ponto de chegada. A relação triangular entre Murnane-Melbourne, Queensland e Kerouac-Califórnia se dá em continentes diferentes, mas dentro da mesma língua. Para o romancista pelotense, a 
distância geográfica pode talvez ser substituída pela distância cultural de um outro idioma.

Em "Um Lugar Mais Tranquilo que Clun" a diferença entre os mundos anglófono e lusófono fica ainda mais nítida. O narrador australiano imagina duas cenas em Melbourne, cria um paralelo nos Estados Unidos, e depois parte para uma sequência de paisagens na Inglaterra. Mesmo se for possível encontrar um par de paisagens brasileiras ou latino-americanas para servir como equivalente para aquelas da costa leste dos EUA, o passo para a Europa é mais complicado. Para o narrador australiano, a Inglaterra representa tanto a origem colonial quanto a autoridade cultural; para um brasileiro, Portugal poderia ser o passado colonial, mas dificilmente representaria qualquer fonte de prestígio no domínio da cultura; seria bem mais plausível (talvez especialmente para um pelotense) imaginar Paris, e não Lisboa, como o centro cultural equivalente a Londres, o que implicaria outra troca de idioma. Além disso, a relação simbólica entre Londres e as paisagens rurais de Hardy e de Housman é bem mais pacífica que a dominação que a Paris do mesmo período exercia sobre o interior francês, tanto na política quanto na literatura. Mesmo aceitando a separação entre passado colonial e presente cultural, e a mudança de português para francês, continua sendo difícil adivinhar como o romancista pelotense resolveria os paralelos, ou como o leitor brasileiro deveria ler o conto original. É plausível um leitor brasileiro identificar a "paisagem literária" com o canto da Península Ibérica onde primeiro se falou português?

E, por fim, o que fazer com "A Batalha de Acosta Nu", com o Paraguai, e com a Nova Austrália? Que tipo de história colonial teria que ser imaginada para criar a possibilidade de um paralelo brasileiro? Para ter um lugar equivalente ao Paraguai, o Murnane pelotense teria que imaginar um país num outro lado do mundo, posicionado entre dois países maiores, produtos de dois impérios europeus, e com uma forte miscigenação entre os colonizadores europeus e a população indígena. Depois, ele teria que imaginar esse país esmagado numa guerra contra os dois países maiores. E, por fim, ele teria que imaginar uma colônia de nordestinos utopistas que se estabelece nesse país derrotado, mas que depois vai se misturando com a população local ao ponto de perder a sua identidade. E esse país ficaria onde? Entre os Estados Unidos e um país imaginário formado pelos falantes de francês na América do Norte? Ou entre dois países imaginários - um de fala inglesa, outro de fala holandesa - no sul da África? 
A própria tentativa de estabelecer qualquer tipo de paralelo cai no absurdo, o que mostra, acima de tudo, a especificidade localizada da obra de Murnane. Se "A Batalha de Acosta Nu" é uma fantasia, é uma fantasia que existe numa relação muito específica com fatos históricos específicos: fatos que encontram sentido dentro dos círculos concêntricos da cultura anglófona, da cultura australiana, da cultura de Melbourne. Nessas obras, a recusa da nação como escala obrigatória não leva Murnane nem para o campo impossivelmente aberto da "literatura mundial" (onde o centro fica sempre escondido, além do horizonte, num gabinete em Harvard, ou Londres, ou Paris), nem para o nacionalismo menor do provinciano, que conhece seu centro mas não pretende ir muito longe. Quando o leitor tem a oportunidade de descobrir que Melbourne pode ser o centro do mundo, que a sua cidade natal pode fazer parte de uma paisagem avistada num copo de cerveja num bar em Melbourne, aquela mesma cidade natal também pode passar a ser o centro do mundo, um lugar a partir de qual se enxerga Melbourne, Buenos Aires, Praga, Luanda, e o que quiser.

\section{Referências}

ACCORSI, Diego. Quien es Robin Wood? Disponível em:

<http://www.robinwoodcomics.org/quienesrobinwood/index.php>. Acesso em: 26 set. 2016.

BORGES, Jorge Luis. O Aleph. In: . Obras completas de Jorge Luis Borges. v. 1. São Paulo: Globo, 1999. p. 686-698.

DIXON, Robert. National Literatures, Scale and the Problem of the World. JASAL: Journal of the Association for the Study of Australian Literature v. 15, n. 3, p. 1-10, 2015.

FLANAGAN, Richard. Does writing matter? Disponível em: <www.themonthly.com.au/issue/2016/october/1475244000/richard-flanagan/doeswriting-matter>. Acesso em: 10 out. 2016.

MURNANE, Gerald. The plains. Melbourne: Text, 2000. [Primeira edição: Melbourne: Norstrilia Press, 1982.]

. Landscape with landscape. Sydney: Sydney University Press, 2003. [Primeira edição: Melbourne: Norstrilia Press, 1985.]

Inland. Richmond: William Heinemann, 1988. 
SOUTER, Gavin. A peculiar people: the Australians in Paraguay. St Lucia: University of Queensland Press, 1991. [Primeira edição: Sydney: Angus \& Robertson, 1968.]

WILDE, W. H. Gilmore, Dame Mary Jean (1865-1962). Disponível em:

<http://adb.anu.edu.au/biography/gilmore-dame-mary-jean-6391> Acesso em: 26 set. 2016.

WILDING, Michael. The Paraguayan experiment. Harmondsworth: Penguin, 1984. 